\title{
In memoriam Jean-Jacques Staub (1938-2019)
}

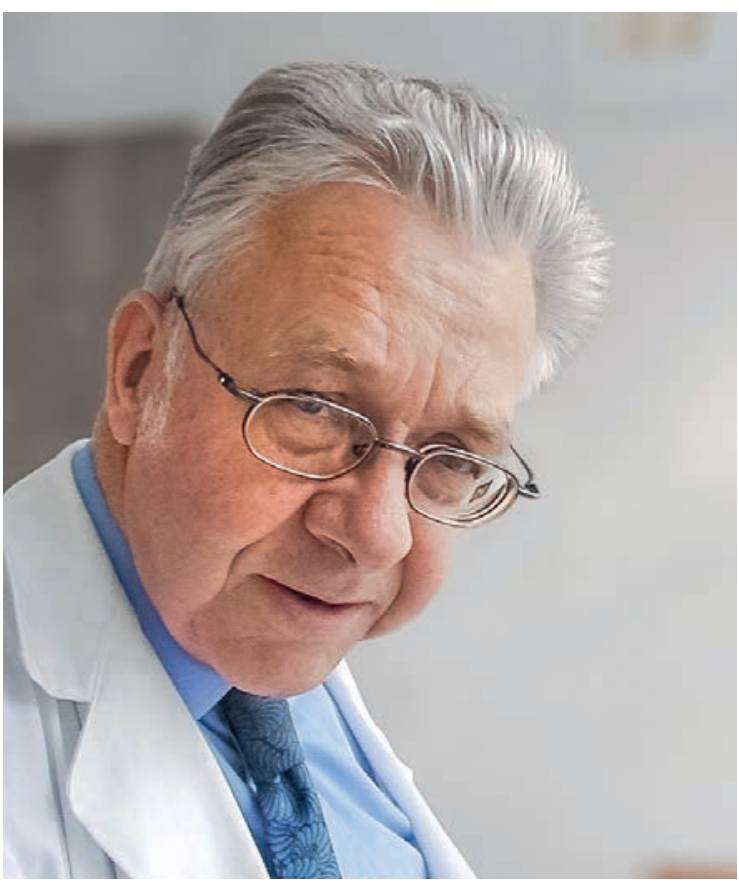

Am 9. Februar 2019 ist nach längerer Krankheit JeanJacques Staub im 81. Altersjahr verstorben. Jean-Jacques Staub prägte in Basel das Gebiet der Endokrinologie.

\section{Von Basel über Paris bis nach London und zurück}

Begonnen hat seine Laufbahn mit dem Medizinstudium in Basel, Genf und Wien, und es folgten Ausbildungs- und Forschungsaufenthalte in Paris und London. Zurück aus England, erhielt er 1975 eine Stelle als Endokrinologe an der Abteilung für Nuklearmedizin und als Konsiliararzt der Medizinischen Poliklinik des damaligen Kantonsspitals Basel. Die Nuklearmedizin ermöglichte zu dieser Zeit neuartige Optionen bei der Diagnostik und Therapie von Schilddrüsenerkrankungen. 1979 wurde er Leiter der Endokrinologie der neu geschaffenen Abteilung Endokrinologie und Diabetologie, und 1985 ernannte ihn die Medizinische Fakultät der Universität Basel zum a.o. Professor.

Die Verfügbarkeit von quantitativen Hormonbestimmungen war die Voraussetzung für eine zuverlässige Funktionsdiagnostik. In Zusammenarbeit mit Jürg
Girard, der Radioimmunoassays für Hypophysen- und Zielorganhormone zur Verfügung stellte, führte JeanJacques erfolgreich grosse klinische Studien mit Funktionstests durch. Sein spezielles Interesse galt der Abklärung von Schilddrüsenstörungen - diese Studien wurden durch Gelder des Schweizerischen Nationalfonds wiederholt unterstützt. Weitere Forschungsprojekte befassten sich mit der HypothalamusHypophysenregulation und der Diagnostik von Nebennierenstörungen. Für die im In- und Ausland vielbeachteten Publikationen erhielten er und sein Team Preise der Schweizerischen Gesellschaft für Innere Medizin und der European Society of Clinical Investigation. Seine mit Akribie verfolgte klinische Forschung war für ihn ebenso wichtig wie eine kompetente und empathische Patientenbetreuung.

\section{Vom Einmannbetrieb zur Abteilung für Endokrinologie}

Unter J.-J. Staub hat sich die Endokrinologie in Basel von einem Einmannbetrieb zu einer universitären Abteilung von beachtlicher Grösse entwickelt. Er förderte beispielhaft die interdisziplinäre Zusammenarbeit mit Nachbargebieten, wie der Nuklearmedizin, der Neuroradiologie, der endokrinen Chirurgie, der Ophthalmologie, der Gynäkologie und der Labormedizin. J.-J. Staub war auch in der Fachgesellschaft für Endokrinologie in der Schweiz aktiv - er war jahrelang deren Sekretär und anschliessend Präsident.

J.-J. Staub gelang es, eine grosse Zahl von Studierenden und Ärztinnen und Ärzten durch fesselnde Vorlesungen für das Fachgebiet der Endokrinologie zu begeistern. Er trat im Jahr 2001 als Abteilungsleiter zurück und betreute noch viele Jahre in Teilzeit und trotz zunehmender körperlicher Behinderung Patienten in einer endokrinologischen Praxis in Basel. Sie alle und wir, die mit Jean-Jacques zusammenarbeiten durften, werden ihn als engagierten Arzt und liebenswürdigen Kollegen in bester Erinnerung behalten.

Prof. emer. Dr. med. Ulrich Keller Ehem. Chefarzt der Klinik für Endokrinologie, Diabetologie und klin. Ernährung, Universitätsspital Basel 